\title{
TRANSESOPHAGEAL ECHO STUDY IN PATIENTS WITH ACUTE ISCHEMIC STROKE
}

\author{
Kamal Saad Mansour, Manar Mostafa Elzaki, Khaled A. M. Elsharkawy*, Waleed Elawady and \\ Al-Shaimaa Ali Mohamad Al-Sadek \\ Cardiology and Neurology* Department, Faculty of Medicine, Zagazig University.
}

\begin{abstract}
Background: Stroke is one of the major causes of death and disability and due to the high mortality and morbidity rates associated with stroke ,it is becoming a major community health problem worldwide. It has been estimated that cardiogenic emboli are a source of transient ischemic attack (TIA) or stroke in $20 \%$ to $40 \%$ of all cases. Transesophageal echocardiography (TEE) has been proven superior to transthoracic echocardiography (TTE) for the detection of potential sources of cardiac embolism in patients with previous stroke. In particular, the additional value of TEE in the patients above 45 years of age, in whom TEE is still far from routine procedure, was evaluated. In addition, emphasis was placed on therapeutic consequences, ie, the indication for anticoagulation, based on the results of TEE.

Aim of the work : The aim of our study is to evaluate the role of TEE (transesophagealecho) to find indications of anticoagulation despite false absence of its benefit by clinical and transthoracicecho (TTE) examination.

Patient and methods: The study was conducted in Zagazig university hospitals and included 100 patients diagnosed with ischemic stroke The diagnosis of stroke was made based on clinical data and brain CT. A full TEE was done and the presence of the following potential sources of embolism was specifically examined (a)left atrial spontaneous echo contrast and thrombus , (b)Impaired Left atrial appendage velocity and the presence of LAA (Left atrial appendage )thrombi , (c)Atheroma in the thoracic aorta, (d)Patent foramen ovale and atrial septal aneurysm (e) others, including valvular vegetations and intracardiac masses . Results:Among the different age groups studied, the prevalence of PFO and MVP (mitral valve prolapse) were highest in patients $<45$ years old while the prevalence of complex aortic atheroma was highest in patients $>45$ years old .Risk of stroke recurrence was highest in patients with complex aortic atheroma .Among patients with dyslipidemia,prevalance of ischemic stroke was highest in those older than 45 years old and was significantly higher in low HDL (high density lipoprotein ) $(<40 \mathrm{mg} / \mathrm{dl}$ ) and high cholesterol $(>200 \mathrm{mg} / \mathrm{dl})$ group.Furthermore, the risk of stroke recurrence was significantly higher in patients with hypercholesterolemia.

Conclusion: TEE has proved to be a very useful tool in diagnosing causes of ischemic stroke .The benefit was not only seen in young age ( $<45$ years old), but also in those in older age groups .

Key words: Mitral valve prolapse, patent foramen ovale, interatrial septal aneurysm , complex aortic ahteroma ,Transesophageal Echocardiography.
\end{abstract}

\section{INTRODUCTION}

Atroke is the leading cause of disability and $\checkmark$ the second most common cause of death worldwide $^{(\mathbf{1})}$. Accurate definition of the mechanism of stroke is crucial as this will guide the most effective care and therapy. Cardioembolic stroke accounts for 14-30\% of all cerebral infarctions ${ }^{(2)}$. In most cases, recurrence of cardioembolism can be prevented by oral anticoagulants. Therefore, for a patient with a cerebral infarct, early confirmation of a diagnosis of cardioembolic infarction is extremely important in order to initiate anticoagulation therapy for an adequate secondary prevention ${ }^{(3)}$.

It has been estimated that cardiogenic emboli are a source of transient ischemic attack (TIA) or stroke in $20 \%$ to $40 \%$ of all cases. Transesophageal echocardiography (TEE) has been proven superior to transthoracic echocardiography (TTE) for the detection of potential sources of cardiac embolism in patients with previous stroke ${ }^{(\mathbf{4})}$. The echocardiographic diagnosis of cardiac thrombi, vegetations and tumors as well as the identification of predisposing conditions such as patent foramen ovale, aortic atherosclerosis and other minor causes (e.g., mitral valve prolapse, mitral and aortic valve calcification) have crucial clinical relevance, affecting the choice of surgery and/or of pharmaceutical therapy in the setting of patients presenting embolism. The echocardiographic assessment helps not only for the retrospective diagnosis 
of sources of embolism but also for the prevention of events in asymptomatic patients. Echocardiography can also distinguish normal variants and artifacts from cardiac masses and tumors $^{(5)}$.

\section{AIM OF THE WORK}

The aim of our study is to evaluate the role of TEE (transesophagealecho) to find indications of anticoagulation despite false absence of its benefit by clinical and transthoracicecho (TTE) examination.

\section{PATIENTS AND METHODS}

This study was carried out in Zagazig University Hospitals, it was conducted from January 2011 to August 2013. It included (100) patients diagnosed with acute ischemic stroke ,the diagnosis of ischemic was based on clinical data and brain CT.

Inclusion criteria: Acute ischemic stroke patients without indication for anticoagulation based on clinical, electrocardiographic and TTE findings.

Exclusion criteria: Patients with a preexisting contraindication to anticoagulation. Patients with a pre-existing indication to anticoagulation (these include: mitral valve stenosis ,Mechanical valve prosthesis, left ventricular systolic dysfunction, dilated \& restrictive cardiomyopathy, previous myocardial infarction,left atrial or left ventriclular masses that where easily detected by TTE) Carotid Dupplex revealing carotid stenosis more than or equal to $\geq 70 \%$. Patients with hypertension or diabetes mellitus.

\section{Our patients were subjected to the following:}

Thorough history taking, physical examination \& investigations : this included thorough neurological and cardiac examination CT -brain standard 12-leads electrocardiogram to exclude the presence of atrial fibrillation laboratory tests for hyperlipidemia (HDL ,LDL ,Serum Total Cholestrol,serum triglyceries) according to ATP3 guidelines in 2004.

* Conventional Transthoracic EchoDoppler study: Transthoracic echocardiographic examination was done by using HP Sonos 5500 set with a $2.5 \mathrm{MHz}$ transducer. Images were taken while the patient in supine or in the left lateral position utilizing left parasternal long axis, apical 4 and apical 2 chamber views. Recordings and calculations of different parameters were performed according to the recommendations of the American Society of Echocardiography M-mode, 2D, and Doppler, according to the recommendations of the American Echocardiography Society.

* Transesophageal echocardiographic examination using (Hewlette Packard) Sonos 5500 set: with a transesophageal echo transducer and with the following preparation Patient was informed to fast for minimum of 4 hours before the procedure,we examined the mouth for loose teeth ,Patients were asked whether there were any problems with swallowing, local anesthesia was given to decrease gag reflex.TEE was performed under conscious sedation

\section{Detailed}

Echocardiography data:

Transesophageal

1-left atrial spontaneous echo contrast and thrombus: Left atrial spontaneous echo contrast was diagnosed by the presence of characteristic dynamic smoke-like swirling echo in the left atrium or the left atrial appendage. Spontaneous echo contrast was graded as $0=$ no smoke, $1+=$ mild smoke visible in some portion of the LA, $2+=$ dense smoke that appeared throughout the LA.

2-Left atrial thrombus was diagnosed by the presence of an echodense mass in the left atrium or the left atrial appendage, distinct from the endocardium and the pectinate muscles of the left atrial appendage.

3-Atheroma in the thoracic aorta: The transesophageal probe is set at $0^{\circ}$ and is rotated counterclockwise to demonstrate the thoracic aorta in cross section. The probe is advanced until the aorta is no longer visualized (approximately $44-50 \mathrm{~cm}$ from the patient's incisors) and is then slowly withdrawn as the aorta is inspected for evidence of atherosclerotic plaque and dissection. To further survey plaque and other vessel wall changes, the imaging plane was increased to $90^{\circ}$ to visualize the long axis of the aorta. As the probe is withdrawn to the upper esophagus, the aortic arch was inspected. The probe was then turned counterclockwise and withdrawn further to better visualize the distal ascending aorta. At the level of the arch, the imaging plane was then increased to $90^{\circ}$. 
Atheroma that is mobile, pedunculated, or protruding $\geq 5 \mathrm{~mm}$ into the lumen are classified as complex atheroma .All other sessile atheroma $<5 \mathrm{~mm}$ in thickness are classified as simple atheroma.

4-Patent foramen ovale and atrial septal aneurysm : Image acquisition at $90^{\circ}$ Imaging plane with clockwise turning demonstrated the bicaval view. In the bicaval view, the interatrial septum traverses horizontally across the screen, and an atrial septal defect can be appreciated with color Doppler. We typically choose this view for agitated saline injection (rest, post-Valsalva, and cough) for a suspected patent foramen ovale, but the $0^{\circ}$ and $135^{\circ}$ orientations, or the $60^{\circ}$ orientation may also be used .

Maintaining the imaging angle at $135^{\circ}$, the probe was turned clockwise to demonstrate the right and left atria and interatrial septum The interatrial septum appears horizontally across the screen, and the fossa ovalis is well visualized. Color Doppler is applied to identify atrial septal defects. Agitated saline injections for patent foramen ovale detection may be performed at this or other orientationsAgitated saline contrast was often performed during TEE in patients with suspected paradoxical embolism due to a patent foramen ovale . For these patients, we usually interrogated the interatrial septum from $0-180^{\circ}$ to identify the best orientation to visualize the thinnest portion of the interatrial septum/fossa ovalis. Saline is administered at rest, followed by injections with cough and post-Valsalva release. Except for cases of suspected persistence of a left sided superior vena cava, our preference is to inject agitated saline from the right arm so as to avoid potential obstruction to venous flow related to the patient's left lateral decubitus position .Atrial septal aneurysm is defined as a thin-walled area in the region of the fossa ovalis with a base of at least $1.5 \mathrm{~cm}$ and an excursion with the cardiac cycle of at least $1.5 \mathrm{~cm}$. Care will be taken to distinguish a true atrial septal aneurysm from a hypermobile interatrial septum .

5-Left atrial appendage (LAA) velocity and LAA thrombi :While maintaining the imaging plane at $90^{\circ}$, the image depth is increased and the TEE probe is turned counterclockwise to obtain the two-chamber view, including the LA, the LV, and the mitral valve .The probe is then withdrawn slightly, anteflexed, and turned more counterclockwise to visualize the LAA at $90^{\circ}$. Pulse wave Doppler is applied to assess emptying velocities ${ }^{(6)}$

\section{Statistical analysis:}

Continuous variables are summarized as mean \pm SD. Variables measured between the 3 age groups, were compared by repeated 1way analysis of variance (ANOVA). Categorical variables were compared by Chisqure. Paired-t test was used to compare continuous variables between groups. All was calculated SPSS version 12 software program (7)

\section{RESULTS \\ The 100 stroke patients were} classified by 3 classifications :1) according to age into 3 groups $<45$ years old (Group $A=32$ patients) , 45-65yrs. (Group $\mathrm{B}=36$ patients) and >65years (Group $\mathrm{C}=32$ patients) .2) according to history of stroke recurrence :Group I ( patients with first time ischemic stroke) and group II (patients with recurrent ischemic stroke). 3) Finally, according to gender into female (F) group and male (M) group.

Demographic and clinical data: the study included 48 females (48\%) and 52 males $(52 \%)$. Their ages ranged from 18 to $82 ; 38$ (38\%) patients had a recurrent stroke as opposed to $62(62 \%)$ first time ischemic stroke patients.

Comparative analysis of TEE parameters in different age groups (table 1):

$38 \%$ of all stroke patients had a normal TEE. However $62 \%$ (26 male, 36 female) had a cardiac abnormality detected, despite normal TTE examination.

A-As regard miral valve prolapse (MVP): The prevalence of mitral valve prolapse (MVP) was $10 \%$ of all our patients (4 male, 6 female) and the highest in patients $<45$ years of age $(25 \%$ of group A).There is a statistically significant difference in prevalence of MVP between group A \& both group B\& $\mathrm{C}$ with the highest prevalence seen in group A (age $<45$ years).

B-PFO: In our study PFO was seen in $10 \%$ of our study population( 2 male, 8 female). The 
prevalence was highest in patients $<45$ years old $(25 \%$ of group A) with a significant difference between groups.

C-ASD: Was found in 4\%(2 male, 2 female) of the study population, (4\%) of group A , no patients in group B and $(6 \%)$ in group $\mathrm{C}$ with no significant difference in prevalence between groups.

D-IASA: Was seen in 4\%(2 male, 2 female) of the study population with no significant difference in prevalence between groups.

E-Complex aortic atheroma : $28 \%$ of our study population(12 male, 16 female) had a complex aortic atheroma in the ascending aorta and arch. The prevalence was highest in patients older than 45 years $2 \%$ in group A, $22 \%$ of group B and $56 \%$ of group C) with a significant difference between groups.

F-Intracardiac masses: Intracardiac masses are seen in $6 \%$ of our study population( 4 male, 2 female) all of them in group A, represent $19 \%$ (3 patients had small vegetations over the aortic valve cusps \& 3 patients with an Aschoff nodule over the mitral valve), none of group $\mathrm{B}$ or $\mathrm{C}$.with a statistically significant difference between groups.

Table (1): Comparative analysis of TEE parameters in different age groups.

\begin{tabular}{|c|c|c|c|c|c|c|c|}
\hline \multirow[b]{2}{*}{ TEE parameters } & \multicolumn{3}{|c|}{ Age group } & \multirow[b]{2}{*}{ Chisq. } & \multirow[b]{2}{*}{ P1 } & \multirow[b]{2}{*}{$\mathbf{P 2}$} & \multirow[b]{2}{*}{ P3 } \\
\hline & $\underset{N=32}{A}$ & $\begin{array}{c}\mathrm{B} \\
\mathrm{N}=36\end{array}$ & $\begin{array}{c}\mathrm{C} \\
\mathrm{N}=32\end{array}$ & & & & \\
\hline MVP No.(\%) & $8(25 \%)$ & $2(36 \%)$ & $0(0 \%)$ & 12.346 & $<0.05$ & $<0.05$ & $>0.05$ \\
\hline PFO No.(\%) & $8(25 \%)$ & $2(36 \%)$ & $0(0 \%)$ & 12.346 & $<0.05$ & $<0.05$ & $>0.05$ \\
\hline ASD No .(\%) & $2(6 \%)$ & $0(0 \%)$ & $2(6 \%)$ & 2.344 & $>0.05$ &.$>0.05$. & $>0.05$ \\
\hline IASA No. (\%) & $2(6 \%)$ & $2(5.6 \%)$ & 0 & 1.982 & $>0.05$ & $>0.05$ & $>0.05$ \\
\hline $\begin{array}{l}\text { Complex aortic } \\
\text { atheroma }\end{array}$ & $2(6 \%)$ & $8(22 \%)$ & $18(56 \%)$ & 20.77 & $>0.05$ & $<0.05$ & $<0.05$ \\
\hline $\begin{array}{l}\text { Intracardiac } \\
\text { masses }\end{array}$ & $6(19 \%)$ & 0 & 0 & 13.56 & $<0.05$ & $>0.05$ & $>0.05$ \\
\hline
\end{tabular}

*MVP=mitral valve prolapse, $\mathbf{P F O}=$ patent foramen ovale ,ASD=atrial septal defect, $\mathbf{I A S A}=$ interatrial septal defect,P1:P-value group A vs. Group B ,P2:group A vs. group C ,P3:group B vs. group C

\section{Comparative analysis of lipid profile in} different age groups (table 2):

Low HDL (<40 mg/dl): Prevalence of low HDL ( $<40 \mathrm{mg} / \mathrm{dl})$ was $50 \%$ in all our study population, $(24$ male, 26 female), increased significantly in patients older than 45 years (31\% of group A, $56 \%$ of group B, and $63 \%$ of group $\mathrm{C}$ ). There is a statistically significantly difference between group A \& the other 2 groups group B \&C with the highest prevalence in group $\mathrm{C}$.

Elevated LDL ( >130 mg/dl): Elevated LDL is detected in $20 \%$ in all our study population,( 8 male, 12 female), $12.5 \%$ of group A , 27.8.\% of group B and (18.8\%) of group C. With no statistically significant difference seen between the groups.

\section{Hypercholesterolemia(> 200mg/d):}

Prevalence of hypercholesterolemia was $11 \%$ in all our study population,(6 male, 5 female), increased with age ( 0 in group A, $22 \%$ of group B and $9 \%$ of group C). A statistically significant difference is seen between group A\& B with the highest prevalence in group B (age 45-65 years).

\section{Hypertriglyceridemia( $>150 \mathrm{mg} / \mathrm{dl})$ :}

Hypertriglyceridemia is detected in was $22 \%$ in all our study population,(10 male, 12 female), $19 \%$ of group A, $27.8 \%$ of group B and $19 \%$ of group C. No statistically significant difference is recorded between the 3 groups 
Table (2): Comparative analysis of lipid profile in different age groups.

\begin{tabular}{|c|c|c|c|c|c|c|c|}
\hline & \multicolumn{3}{|c|}{ Age group } & \multirow[b]{2}{*}{ Chisq. } & \multirow[b]{2}{*}{ P1 } & \multirow[b]{2}{*}{$\mathbf{P 2}$} & \multirow[b]{2}{*}{$\mathbf{P 3}$} \\
\hline & $\underset{\mathrm{N}=32}{\mathrm{~A}}$ & $\underset{N=36}{B}$ & $\begin{array}{c}\mathrm{C} \\
\mathrm{N}=32\end{array}$ & & & & \\
\hline Low HDL No.(\%) & $10(31 \%)$ & $20(56 \%)$ & $20(63 \%)$ & 18.9 & $<0.05$ & $<0.05$ & $>0.05$ \\
\hline Elevated LDL No.(\%) & $4(12.5 \%)$ & $10(27.8 \%)$ & $6(18.8)$ & 2.5 & $>0.05$ & $>0.05$ & $>0.05$ \\
\hline $\begin{array}{l}\text { Hypercholesterolemia } \\
\text { No. }(\%)\end{array}$ & 0 & $8(22 \%)$ & $3(9 \%)$ & 8.7 & $<0.05$ & $>0.05$ & $>0.05$ \\
\hline $\begin{array}{l}\text { Hypertriglyceridemia. } \\
\text { No. }(\%) \\
\end{array}$ & $6(19 \%)$ & $10(28 \%)$ & $6(19 \%)$ & 1.1 & $>0.05$ & $>0.05$ & $>0.05$ \\
\hline
\end{tabular}

*HDL: high density lipoprotein, LDL: low density lipoprotein. P1:P-value group. A vs. Group B ,P2:group A vs. group C ,P3: group B vs. group C

Comparative analysis of TEE parameters of group I (first time ischemic stroke) \& group II(recurrent stroke) (table 3):

1-MVP: Mitral valve prolapse was seen in $12.9 \%$ of first time stroke group as opposed to $5.3 \%$ of recurrent stroke group. There was no statistically significant difference seen between both groups.

2-PFO: PFO was seen in $13 \%$ of first time stroke group as opposed to $5 \%$ in recurrent group. No statistically significant difference was seen between groups .

3- Atrial septal defect: Was seen in (3.2\%) in group I compared to $(5.3 \%)$ in group II. No statistically significant difference was seen between both groups .

4-IASA: IASA was seen in $3.2 \%$ of first time stroke group as opposed to $5.3 \%$ of recurrent stroke group with no statistically significant difference seen between groups.

5-Complex aortic atheroma: There was a higher prevalence of complex aortic atheroma in the recurrent stroke group $(42 \%)$ as opposed to $19 \%$ in first time ischemic stroke group with significant difference.

6-Intracardiac masses: Were seen in (3.2\%) of group I and (10.5\%) of group II. No statistically significant difference was seen between both groups.

Table (3): Comparative analysis of TEE parameters of group I (first time ischemic stroke) \& group II (recurrent stroke).

\begin{tabular}{lcccc}
\hline \multirow{2}{*}{ TEE Parameters } & \multicolumn{2}{c}{ Recurrent stroke } & & Chisq. \\
\cline { 2 - 4 } & $\begin{array}{c}\text { I } \\
\text { (first time ischemic } \\
\text { stroke) } \\
(\mathrm{N}=62)\end{array}$ & $\begin{array}{c}\text { II } \\
\text { (recurrent stroke) } \\
(\mathrm{N}=38)\end{array}$ & & \\
\hline MVP No. (\%) & $8(13 \%)$ & $2(5 \%)$ & Fischer Exact & $>0.05$ \\
\hline PFO No. (\%) & $8(13 \%)$ & $2(5 \%)$ & Fisher Exact & $>0.05$ \\
\hline ASD & $2(3.2 \%)$ & $2(5 \%)$ & Fischer Exact & $>0.05$ \\
\hline IASA & $2(3.2 \%)$ & $2(5 \%)$ & Fischer Exact & $>0.05$ \\
\hline Complex aortic atheroma & $12(19 \%)$ & $16(42 \%)$ & 6 & 0.01 \\
\hline Intracardiac masses & $2(3.2 \%)$ & $4(10.5 \%)$ & Fisher Exact & $>0.05$ \\
\hline
\end{tabular}

*MVP=mitral valve prolapse , $\mathbf{P F O}=$ patent foramen ovale , $\mathbf{A S D}=$ atrial septal defect,IASA=interatrial septal defect

Comparative analysis of TIAs in different age groups (table 4):

TIAs were seen in $38 \%$ of all patients in our study: $31 \%$ of group A, $39 \%$ of group B and $44 \%$ of group C. No statistically significant difference was seen between the 3 groups.

History of TIAs was seen in $(29.2 \%)$ of females \& $(46.2 \%)$ of males. No statistically significant difference was seen between groups. 
Table 4: Comparative analysis of TIAs in different age groups

\begin{tabular}{cccccc}
\hline \hline & \multicolumn{3}{c}{ Age group } & Chisq. & P.value \\
\cline { 2 - 5 } & $\mathbf{A}$ & $\mathbf{B}$ & $\mathbf{C}$ & & \\
\hline TIAs No.(\%) & $10(31 \%)$ & $14(39 \%)$ & $14(44 \%)$ & 1.1 & $>\mathbf{0 . 0 5}$ \\
\hline
\end{tabular}

*TIAs: transient ischemic attacks

Comparative analysis of patients with vascular territory infarction in different age groups (table 5):

1-Anterior circulation infarction: $93.8 \%$ of group A, $94.4 \%$ of Group B and $100 \%$ of group C. Also equal percentage of males and females $(96 \%)$ had anterior circulation infarction. There was no statistically significant difference between the 3 age groups and both sexes.

2-Posterior circulation infarction: $13 \%$ of group A ; 6\% of the group B and 13\% of group C. Also $13 \%$ of females and $8 \%$ of males had posterior circulation infarction. No statistically significant difference was found between the three groups and both sexes.

Table (5): Comparative analysis of patients with vascular territory infarction in different age groups.

\begin{tabular}{|c|c|c|c|c|c|}
\hline \multirow[b]{2}{*}{ Vascular territory } & \multicolumn{3}{|c|}{ Age group } & \multirow[b]{2}{*}{ Chisq. } & \multirow[b]{2}{*}{ P.value } \\
\hline & $\begin{array}{c}\mathrm{A} \\
\mathrm{N}=32\end{array}$ & $\begin{array}{c}B \\
N=36\end{array}$ & $\begin{array}{c}\mathrm{C} \\
\mathrm{N}=32\end{array}$ & & \\
\hline $\begin{array}{l}\text { Anterior circulation } \\
\text { No . }(\%)\end{array}$ & $30(94 \%)$ & $34(94 \%)$ & $32(100 \%)$ & 1.9 & $>0.05$ \\
\hline $\begin{array}{l}\text { Posterior circulation } \\
\text { No . }(\%)\end{array}$ & $4(13 \%)$ & $2(6 \%)$ & $4(13)$ & 1.2 & $>0.05$ \\
\hline
\end{tabular}

Comparative analysis of neurological parameters in different age groups(table 6): **Aphasia: Was found in $16 \%$ of all our patients( 4 male, 12 female), $13 \%$ of group A, $22 \%$ of group B and $13 \%$ of group C. No significant difference was seen between groups

**Ataxia: Was in $10 \%$ of all our patients( 4 male, 6 female), $13 \%$ of group A had ataxia , $6 \%$ of group B and $13 \%$ of group C. No statistically significant difference was seen between the groups

**Sensory Deficit: Was in $64 \%$ of all our patients (30 male,34female) $56.2 \%$ of group A had a sensory deficit ,50\% of group B and 88 $\%$ of group C . A statistically, significant difference was found between the group $\mathrm{C}$ \&both group A \&B with a higher prevalence of sensory deficit in group $\mathrm{C}$.
**Motor Deficit: Was in $40 \%$ of all our patients(24 male, 16 female), $50 \%$ of group A had a motor deficit $44 \%$ of group B and $25 \%$ of group C. No statistically significant difference was seen between the groups.

**Conscious Level: Percentage of fully conscious patients was $76 \%$ of all our patients(42 male, 34 female), $94 \%$ in group A, $83 \%$ of group B and $50 \%$ of group C. The percentage of confused patients was $20 \%$ of all our patients( 8 male, 12 female), $6 \%$ of group A , $11 \%$ of group B and $44 \%$ of group C were confused. No patients were comatosed in group A, but $5.5 \%$ of group B and $6.2 \%$ of group $\mathrm{C}$ were comatosed (2 male and 2 female). There is a statistically significant difference between the groups as regard the conscious level. More conscious patients were in the younger age group while the older group had a larger number of confused patients. 
(table 6): Comparative analysis of neurological parameters in different age groups

\begin{tabular}{|c|c|c|c|c|c|c|c|}
\hline \multirow[b]{2}{*}{ Neurological examination } & \multicolumn{3}{|c|}{ Age group } & \multirow[b]{2}{*}{ Chisq. } & \multirow[b]{2}{*}{ P1 } & \multirow[b]{2}{*}{$\mathbf{P 2}$} & \multirow[b]{2}{*}{$\mathbf{P 3}$} \\
\hline & $\begin{array}{c}\mathrm{A} \\
\mathrm{N}=32\end{array}$ & $\begin{array}{c}\mathbf{B} \\
\mathrm{N}=36\end{array}$ & $\begin{array}{c}\mathrm{C} \\
\mathrm{N}=32\end{array}$ & & & & \\
\hline Aphasia No. (\%) & $4(13)$ & $8(22)$ & $4(13)$ & 1.620 & $>0.05$ & $>0.05$ & $>0.05$ \\
\hline $\operatorname{Ataxia}$ No. $(\%)$ & $4(13)$ & $2(6)$ & $4(13)$ & 1.235 & $>0.05$ & $>0.05$ & $>0.05$ \\
\hline Sensory Deficit No.(\%) & $18(56)$ & $18(50)$ & $28(88)$ & 11.6 & $>0.05$ & $<0.05$ & $<0.05$ \\
\hline Motor Deficit No.(\%) & $16(50)$ & $16(44)$ & $8(25)$ & 1.7 & $>0.05$ & $>0.05$ & $>0.05$ \\
\hline Conscious & $30(94)$ & $30(83)$ & $16(50)$ & & & & \\
\hline C.L. Confused & $2(6)$ & $4(11)$ & $14(44)$ & 19.8 & $<.01$ & $>0.05$ & $>0.05$ \\
\hline$\overline{\text { Coma }}$ & $0(0.0)$ & $2(5.5)$ & $2(6.2)$ & & & & \\
\hline
\end{tabular}

P1:P-value group A vs. Group B ,P2:group A vs. group C , P3: group B vs. group C

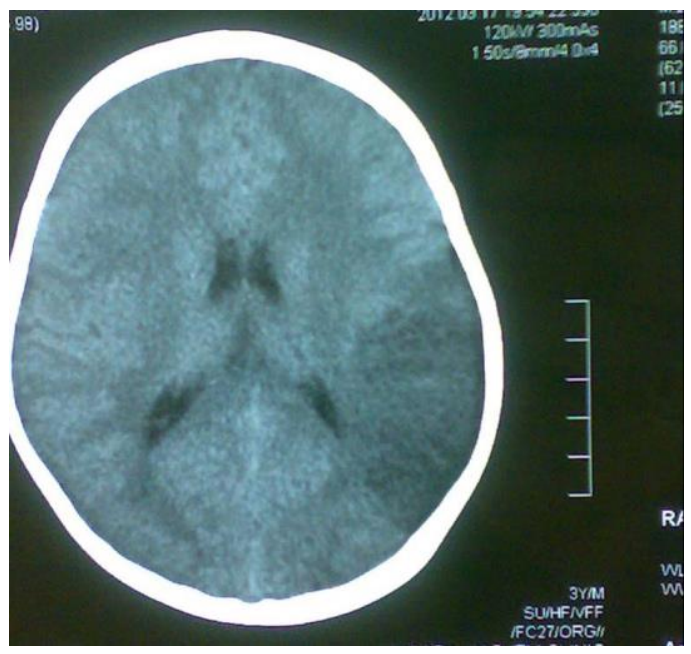

Midesophageal ascending aorta short axis view:ascending aortic atheroma protruding into the lumen measuring $7.5 \mathrm{~mm}$

Axial CT scan of the brain demonstrating left temproparietal infarction.

DISCUSSION

Our study included the following TEE (transesophagealecho) parameters: MVP, PFO, IASA, ASD, complex atheroma, Intracardiac masses.

In our study, $62 \%$ of study population showed posistive findings with TEE that require anticoagulation without other indications for anticoagulation by clinical, electrocardiographic or TTE data.This percentage was higher than the percentage detected by Tiago et al $^{(\mathbf{8})}$ which was $32.1 \%$.However Tiago et al included hypertensive and diabetic patients which were excluded from our study.

The superiority of TEE over TTE for diagnosing cardiac sources of embolism has also been demonstrated by several other studies McNamara et al. ${ }^{\left({ }^{(9)}\right.}$; Blum et al. ${ }^{(10)}$

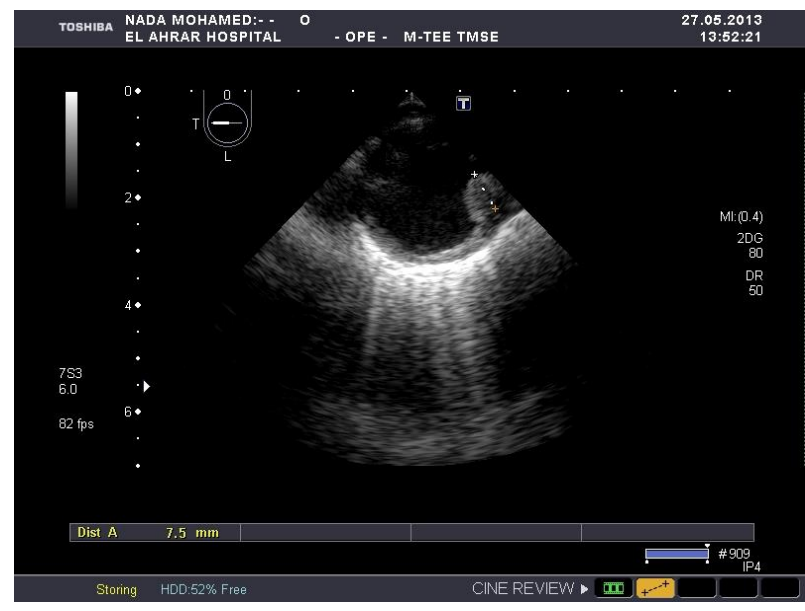

and confirmed in our study. They concluded that "TEE is indispensable in all patients being candidates for oral anticoagulation". Our results seem to confirm their findings, but on a more selected population of patients with no other indication for anticoagulation.

The issue of age is an important one in the discussion on whether TTE or TEE should be used in patients with ischemic stroke. In our study 28 cases ( $87.5 \%$ ) of the patients $<45$ years old had a cardiac source of embolism detected by TEE. this was higher than that detected by Sebastian et al ${ }^{(4)}$, they demonstrated that $33 \%$ of their population $<45$ years old had a cardioembolic source detected by TEE. However ,they enrolled all patients with a TIA or ischemic stroke regardless of any major risk factors or arrhythmias. This may have contributed to smaller percentage of findings.

In our study 34 cases $(50 \%)$ of the patients $>45$ years old had a cardiac source detected by TEE. This figure was bigger than 
that detected by Sebastian et al ${ }^{(4)}$.In their study, TEE demonstrated a risk factor of ischemic stroke in $17 \% \quad(\mathrm{n}=32$ patients). These patients would have been incorrectly denied anticoagulation therapy if only TTE was used. Thus, the current observations support the additional value of TEE in both younger and older patients.

In our study PFO was seen in $10 \%$ of our study population .This was greater than that detected by Tiago et $\mathbf{a l}^{(\mathbf{8}) \text {, they }}$ performed TEE for 84 ischemic stroke patients and $3.6 \%$ only had a PFO. Strandberg, et al $^{(11)}$, studied 441 ischemic stroke patients by TEE and detected 67 PFOs $(15.2 \%)$ of their population .

However, De Castro et al ${ }^{(\mathbf{1 2})}$ studied 350 ischemic stroke patients, and $21 \%$ of their population had a PFO .

This variability in number of PFOs detected by different studies has been explained by Decastro et $\mathbf{a l}^{(\mathbf{1 2})}$, they stated that the prevalence of a PFO as assessed by transesophageal contrast echocardiography varies considerably among echocardiographic laboratories (ranging from 8 to $54 \%$ ). This striking difference may be due to several reasons: (1) the population studied (age, healthy persons versus patients, history of embolism); (2) the technique used (contrast agent, provocative maneuvers, ultrasonic instrumentation including transducer frequency); and (3) the criteria applied for diagnosis.

In our study ASA was seen in $4 \%$ of the study population. This was similar to De Castro et al ${ }^{(12)}$ \& Strandberg, et al ${ }^{(11)}$ Using TEE, they identified atrial septal aneurysms in approximately $4 \%$ of all patients studied. It has been postulated that perhaps these abnormalities provide a nidus for thrombus formation and blood stasis and therefore constitute a risk factor for cerebral embolization.

A higher figure was detected by Rettig et al ${ }^{(\mathbf{1 3})}$, they recorded 7 ASA in 84 ischemic stroke patients $(8 \%$ of their population). However this difference may be attributed to the difference in population studied. Rettig et al ${ }^{(\mathbf{1 3})}$ included patients with TIAs also which were not part of our study population. A higher percentage was also seen in study held by Tiago et al ${ }^{(\mathbf{8})}$ found $10 \%$ had an IASA. However, Tiago et al $^{(\mathbf{8})}$ didn't exclude any of the traditional risk factors so the probability that the ASA is incidental and not the cause of ischemic stroke is higher .

In our study, $28 \%$ of our study population had a complex aortic atheroma in the ascending aorta and arch, this was higher than that detected by Harloff et $\mathbf{a l}^{(\mathbf{1 4})}$. In their study, TEE was performed on 503 ischemic stroke patients. They detected complex aortic atheroma in $19.7 \%$. it was also higher than those detected by Hyun-Ji Cho et al ${ }^{(15)}$ ,they performed TEE for 1833 consecutive ischemic stroke patients with normal sinus rhythm and no history of cardiac disease .They investigated the frequency of aortic plaques in such patients and detected 157 patient (8.5\%).On the other hand, our results were smaller than those detected by Toyoda et al $^{(\mathbf{1 6})}$ using TEE they evaluated complicated lesions in the thoracic aortas of 62 patients who met clinical criteria for embolic stroke. Twenty-six patients (42\%) showed complicated aortic arch lesions on transesophageal echocardiogram.

We believe that this variability in results arouse from interobserver variability in interpretation of arch atheromasand measuring them ,However, all of the studies confirmed the importance of TEE in detecting atheromas in both the ascending aorta and arch.

In our study, the prevalence of mitral valve prolapse (MVP) was $10 \%$ of all our patients and the highest in patients <45 years of age ( $25 \%$ of group A) with significant difference. This was in agreement with Scharf et al ${ }^{(17)}$, they studied the incidence of MVP in 47 patients under 45 years of age with TIA or stroke of unknown cause and in an age- and sex-matched control group. They concluded that the incidence of MVP is higher in young patients with cerebral ischemia of unknown cause than in asymptomatic controls. Similarly Nishimura et $\mathbf{~ a l ~}^{(\mathbf{1 8})}$ followed 237 minimally symptomatic or asymptomatic patients by echocardiography for a mean of 6.2 years. 97 patients with redundant mitral valve leaflets identified by echocardiographically, $10.3 \%$ had sudden death, infective endocarditis, or a cerebral 
embolic event. During the follow-up period, 10 patients (mean age 50 years) sustained a cerebral embolic event.

Jean-Francois et al $^{(19)}$, studied 777 patients with a mean age of 45 years and they found a high risk of stroke during follow-up of these patients. The high stroke risk among patients with MVP and in sinus rhythm can be explained by mitral thickening (which is a major part of the pathology in MVP) which carries a high risk of thrombus formation.

Our results however were discordant with Gilon et al. ${ }^{(20)}$,they performed a casecontrol study, and reviewed data on 213 consecutive patients 45 years of age or younger with documented ischemic stroke or transient ischemic attack. The prevalence of prolapse in these patients was compared with that in 263 control subjects without known heart disease. Mitral-valve prolapse was present in 4 of the 213 young patients with stroke (1.9 percent), as compared with 7 of the 263 controls (2.7 percent); prolapse was present in 2 of 71 patients (2.8 percent) with otherwise unexplained stroke. They concluded that Mitral-valve prolapse is considerably less common than previously reported among young patients with stroke or transient ischemic attack, including unexplained stroke, and no more common than among controls.

An elaborate explanation was given by Boudoulas and Boudoulas in (21) about the mechanisms by which mitral valve prolapse can cause thromboembolism. The pathology of the FMV ( floppy mitral valve )differs significantly from the normal mitral valve. The most specific histopathologic characteristics are collagen dissolution and disruption in the pars fibrosa of the mitral valve leaflets. Also, there is a replacement of the dense collagenous fibrosa by loose myxomatous connective tissue .Similar histologic abnormalities have been seen in chordae tendineae. Scanning electron photomicrographs have demonstrated surface folds and focal loss of endothelial cells of mitral valve leaflets, and these surface abnormalities may predispose to thromboembolic complications and infective endocarditis. Continuous pressure and stress due to left ventricular systole on the mitral valve leaflets and chordae tendineae contribute to the gradual progression of these histologic changes .

We also found that the prevalence of PFO was highest in patients $<45$ years old $(25 \%)$. These results were in agreement with Lechat et $\mathbf{a l}^{(22)}$ they studied the prevalence of patent foramen ovale as detected by contrast echocardiography in a population of 60 adults under 55 years old with ischemic stroke and a normal cardiac examination. they compared the results with those in a control group of 100 patients. The prevalence of patent foramen ovale was significantly higher in the patients with stroke ( 40 percent) than in the control group (10 percent).Thy concluded that These results suggest that because of the high prevalence of clinically latent venous thrombosis, paradoxical embolism through a patent foramen ovale may be responsible for stroke more often than is usually suspected. Similarly Handke et al (23) stated that there's a strong significant association between cryptogenic stroke and PFO in younger patients .This can be explained by the fact that younger patients are less likely to have conventional ischemic stroke risk factors (hypertension, high cholesterol, diabetes mellitus, smoking) and so the probability that a PFO is the cause of stroke increases.

Several postulated mechanisms were

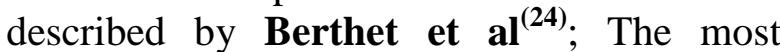
famous is "paradoxical embolism", which is the passage of a thrombus from the peripheral venous system to the left cardiac cavities through the PFO which seems to be the most likely mechanism in patients with cryptogenic stroke associated to PFO, other potential mechanisms should also be considered. One proposed mechanism is in situ thrombus formation within the foramen ovale channel itself. Alternatively, patients with PFO may be more susceptible to atrial fibrillation, due to an altered atrial electrical substrate

We found no statistically significant difference in the prevalence of interatrial septal aneurysm between the 3 age groups $6 \%$ of group A, $5.6 \%$ of group B and none in group $\mathrm{C}$ ). This was in disagreement with Jin Oh Na et al ${ }^{(25)}$,who detected 114 
patients (16.7\%) with interatrial septal aneurysms, among 682 patients diagnosed with cryptogenic stroke.

Although Jin Oh Na et al ${ }^{(25)}$,claimed to study 114 subjects with an ASA. Out of these 114 subjects, PFO was found in 71 subjects and AF was detected in 5 subjects during a 6-month follow-up. Therefore, the study finally consisted of 38 subjects who had ASA alone and 38 matched controls. Furthermore asymptomatic episodes of paroxysmal AF may have contributed to the occurrence of stroke and not the IASA itself.

In our study no statistically significant difference in the prevalence of ASD was seen between the age groups( $6 \%$ of group A , none of group B and $6 \%$ of group C).This was not matched with Bannan et al ${ }^{(26)}$ who studied 329 adult patients, all of them had a secundum type ASD. They found that (14\%) of the study population presented with a paradoxical embolism. These patients tended to be younger and had smaller defects (both by size and shunt ratio) than ASD patients without paradoxical embolism .In our study we had only 4\% ASDs detected in all patients, the marked difference in sample size may explain the difference in results

The prevalence of complex aortic atheroma was highest in patients older than 45 years $6 \%$ in group A, $22 \%$ of group B and $56 \%$ of group C) with significant difference. These results were in concordance with Kate et al ${ }^{(27)}$, who stated that older age was likely associated with complex aortic plaque as a high risk source .However they defined older age as patients $\geq 66$ years old . The gap left between groups (45-66 years ) can be explained by the higher life expectancy in developed countries and higher quality of medical services which guarantees earlier diagnosis and management of risk factors .

In discordance with our results was one population-based study by Russo et $\mathbf{a l}^{(28)}$ after adjustment for risk factors, large aortic arch plaques were not associated with combined vascular events. Associated cofactors, notably hyperlipidemia, may be the underlying cause for the previously described association between plaque and stroke.

In our study low HDL $(<40 \mathrm{mg} / \mathrm{dl})$ was seen as a significant risk factor of stroke in patients older than 45 years .This was in agreement with Goya et al ${ }^{(29)}$, who studied 7735 British men,whose age ranged from 40 to 59 years of age and followed -up these patients for 16.8 years. They stated that those who developed ischemic stroke were significantly older and had lower HDL concentrations (most of them were smokers and less physically active ). However, our findings were different from Rojas et al ${ }^{(30)}$ who studied 535 patients with ischemic stroke or transient ischemic attack (TIA); A total of 179 were over 80 years $(33.5 \%)$. They concluded that hyperlipidemia was more frequent in the group younger than 80 .

Our study also showed that prevalence of hypercholesterolemia increased with age .This was in agreement with Cholesterol $\begin{array}{lll}\text { Treatment } & \text { Trialists' } & \text { (CTT) }\end{array}$ Collaborators $^{(31)}$, who studied 90056 patients with hypercholesterolemia \& they found that the proportional reduction in major vascular events differed significantly according to the absolute reduction in cholesterol achieved.

Our study in all patients also showed that prevalence of low HDL was $50 \%$, hypertriglyceridemia was $22 \%$, elevated LDL was $20 \%$ and hypercholesterolemia was $11 \%$. Symptomatic intracranial atherosclerosis is strongly associated with low HDL-C, high triglyceride and hypercholesterolemia whereas extracranial atherosclerosis is not. Mechanisms by which these risk factors contribute to the high risk of stroke in patients with intracranial stenosis still remain unclear. One explanation may be that the association of atherogenic dyslipidemia with a proinflammatory state and oxidative stress contribute to the residual vascular risk. ${ }^{(32)}$

In our study, we found no significant difference between groups regarding prevalence of low LDL- cholesterol.This was discordant with Heiss et al ${ }^{(33)}$, Moulopoulos et al ${ }^{(34)}$, Heitmann et al ${ }^{(35)}$ and Schaefer et al ${ }^{(36)}$. They performed cross-sectional studies and concluded that LDL cholesterol levels tend to increase with age. on the other hand, Newschaffer et al ${ }^{(37)}$, Frishman et al ${ }^{(38)}$ and Garry et al ${ }^{(39)}$ all performed prospective studies of participants $\geq 65$ years of age and 
reported that total and LDL cholesterol levels decrease with age.

In our study, there was no significant difference between the age groups .regarding hypertriglyceridemia (19\% of group A, $28 \%$ of group B and $9 \%$ of group C). This was in agreement with Bowman et al $^{(40)}$; They found no correlation between non fasting triglycerides and ischemic stroke was found. In another case-control study conducted by Sridharan et al ${ }^{(41)}$ fasting triglyceride level were studied in 204 patients with acute ischemic stroke and 204 controls, they did not find any significant association between fasting triglycerides and acute ischemic stroke.

A third prospective study, the Atherosclerosis Risk in Communities(ARIC) study ${ }^{(42)}$, showed only a weak and inconsistent association between fasting triglyceride levels and ischemic stroke. The ARIC study included a cohort of 14,175 men and women who were free of prior clinical cardiovascular disease and who were followed prospectively for a mean of 10 years. In that study, there was no significant association between IS and fasting lipid levels (LDL-C, HDL-C, and triglycerides) reported in either gender.

Our results were not matched with the

Blood Lipids and First-Ever Ischemic Stroke/Transient IschemicAttack in the Bezafibrate Infarction Prevention (BIP) registry $^{(\mathbf{4 3})}$, a large prospective trial of 11,177 patients with known underlying coronary heart disease, fasting hypertriglyceridemia was found to be an independent risk factor for the development of first-ever ischemic stroke or TIA.

Similarly, the meta-analysis of prospective studies by the Asia-Pacific Cohort Studies Collaboration (APCSC) ${ }^{(44)}$ in 2004 , included 96,224 individuals,. In $90 \%$ of the participants the triglyceride levels were measured after fasting. The results indicated a significant association between elevated serum triglycerides and ischemic stroke that was independent of other major measured risk factors.

However, our study didn't include patients with major risk factors for ischemic stroke including hypertension and diabetes mellitus. All the above studies included these patients and this may explain the difference in results .

Anette et al ${ }^{(45)}$, measured baseline non-fasting triglycerides in 7,579 women and 6,372 men and followed them up to 33 years; They concluded that stepwise increasing levels of non fasting triglycerides were associated with increased risk of ischemic stroke. The difference in results can be attributed to the discrepancy in methodology applied.

In our study, there was a higher prevalence of patients with complex aortic atheroma in the recurrent stroke group. This was matched with Marco et $\mathbf{a l}^{(46)}$ who concluded that complex aortic atheroma were associated with a significantly increased risk of recurrent events. This can be explained easily as Large aortic arch plaques have a definite embolic potential, demonstrated by the frequent microembolic signals observed by transcranial Doppler.The stroke mechanism in patients with large or complex aortic plaques is believed to be predominantly thromboembolic.

TIAs were seen in $38 \%$ of all patients in our study: $31 \%$ of group A, $39 \%$ of group $\mathrm{B}$ and $44 \%$ of group $\mathrm{C}$. There was no statistically significant difference seen between groups but indicate that TIAs increase with age. This was in agreement with Kleindorfer et al $^{(47)}$, who stated that the incidence of TIAs increases with age, from 13 cases per 100,000 in those younger than 35 years to as many as 1500 cases per 100,000 in those older than 85 years.

Furthermore, Ayeesha et al ${ }^{(48)}$ studied five hundred and forty five individuals 35 years of age or older the patients were screened for past stroke or TIA, (19.1\%) were observed to have a prior stroke while TIA was found in $(9.7 \%)$. They thus concluded that older age, was significantly associated with a higher prevalence of TIAs.

In our study, no statistically significant difference was seen between different age groups in the prevalence of anterior circulation infarction (94\% of group A, $94 \%$ of group B and $100 \%$ of group C. This was not matched with Huang et

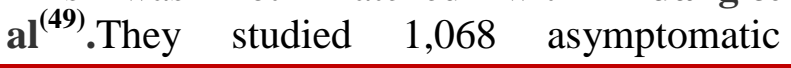


subjects over 50 years of age by transcranial Doppler. Middle Cerebral Artery stenosis was found in 63 subjects $(5.9 \%)$. They concluded that older age is an independent risk factor of middle cerebral artery infarction. Similarly, Jukka et $\mathbf{a l}^{(50)}$ who performed a retrospective observational study that evaluated 1008 patients aged 15-49 years. They concluded that anterior circulation infarcts were more common among older patients.

We found no statistically significant difference between age groups regarding the prevalence of posterior circulation infarction (13\% of group A, $6 \%$ of group B and $13 \%$ of group C). This was not matched with Jukka et al ${ }^{(50)}$. They concluded that posterior circulation infarcts were more common among patients <45 years of age, the latter being mostly attributable to cerebellar lesions They explained this finding by the fact that more vertebral artery dissections are causing stroke in this age group.

We found no significant difference in prevalence of sensory deficit, motor deficit, ataxia, aphasia or impaired conscious level between the different age groups. this was not matched with Margaret et $\mathbf{a l}^{(51)}$. They studied patients using the Framingham Study cohort, they concluded that .Older age at stroke onset, not gender or stroke subtype, was associated with greater disability .

\section{CONCLUSION}

TEE has proved to be a very useful tool in diagnosing causes of ischemic stroke. The benefit was not only seen in young age $(<45$ years old), but also in those in older age groups. TEE can have therapeutic implications in ischemic stroke patients in sinus rhythm and with a previous TTE with no indication for anticoagulation. We recommend using transesophageal edchocardiogram in patients with ischemic stroke in whom ,ECG and transthoracic echo failed to identify a cardiac source of embolism. We also recommend the use of TEE on a larger sector of patients \& in interventional and follow-up studies to assess whether or not anticoagulants decrease the size of complex aortic atheroma

\section{REFERENCES}

1-Ferro JM. Brain embolism. Answers to practical questions. J Neurol. 2003;250:139-47.

2- Khoo CW, Lip GYH. Clinical outcomes of acute stroke patients with atrial fibrillation. Expert Rev Neurother. 2009;7:371-4.

3-Adrià Arboix and Josefina Alió . Cardioembolic Stroke: Clinical Features, Specific Cardiac Disorders and Prognosis. Curr Cardiol Rev. 2010 August; 6(3): 150-161.

4-Sebastiaan F.T.M. de Bruijn, Willem R.P. Agema, Gert Jan Lammers, Ernst E. van der Wall, Transesophageal Echocardiography Is Superior to Transthoracic Echocardiography in Management of Patients of Any Age With Transient Ischemic Attack or Stroke. Stroke. 2006;37:2531-2534.

5- Pepi M, Evangelista A, Nihoyannopoulos $\mathrm{P}$ et al. For the European Association of Echocardiography (EAE).Recommendations for echocardiography use in the diagnosis and management of cardiac sources of embolism. Eur. J. Echocardiogr.11,461-476 (2010).

6-Min JK, Spencer KT, Furlong KT, DeCara JM, Sugeng L, Ward RP, et al. Clinical features of complications from transesophageal echocardiography: a single-center case series of 10,000 consecutive examinations. J Am Soc Echocardiogr. 2005;18:925-9.

7- Dean JA and Coulabier D. A word processing database and statistic program for epidemiology on microcomputer CDC, Atlanta, Gorgia, USA (2000).

8-Tiago Tribolet de Abreu, Sonia Mateus, Cecilia Carreteiro, and Jose Correia. Therapeutic implications of transesophageal echocardiography after transthoracic echocardiography on acute stroke patients. Vasc Health Risk Manag. 2008 February; 4(1): 167172.

9--McNamara RL, Lima JAC, Whelton PK, et al. Echocardiographic identification of cardiovascular sources of emboli to guide clinical management of stroke: a costeffectiveness analysis. Ann Intern Med. 1997; 127:775-87

10- Blum A, Reisner S, Farbstein Y. Transesophageal echocardiography vs. transthoracic echocardiography in assessing cardio-vascular sources of emboli in patients with acute ischemic stroke. Med Sci Monit. 2004;10:CR521-3.

11- Strandberg M, Marttila RJ, Helenius H, Hartiala J. Transoesophageal echocardiography in selecting patients for anticoagulation after ischaemic stroke or transient ischaemic attack. JNNP. 2002; 73: 29-33.

12- De Castro S, Cartoni D, Fiorelli M, Rasura M, Anzini A, Zanette EM, Beccia M, Colonnese C, 
Fedele F, Fieschi C, Pandian NG. Morphological and functional characteristics of patent foramen ovale and their embolic implications. Stroke 2000; 31(10): 2407-13

13-T.C.D. Rettig, B.J. Bouma,and R.B.A. van den Brink. Influence of transoesophageal echocardiography on therapy and prognosis in young patients with TIA or ischaemic stroke. Neth Heart J. 2009 October; 17(10): 373-377.

14-Harloff A, Handke M, Reinhard M, et al. Therapeutic strategies after examination by transesophageal echocardiography in 503 patients with ischemic stroke. Stroke. 2006;37:859-64

15-Hyun-Ji Cho , Hye-Yeon Choi , Young Dae Kim , Hyo Suk Nam, Sang Won Han, Jong Won Ha, Nam-Sik Chung, Ji Hoe Heo. Transesophageal echocardiography in acute stroke patients with sinus rhythm and no cardiac disease history.J Neurol Neurosurg Psychiatry doi:10.1136/jnnp.2009.190322 .

16- Toyoda K, Yasaka M, Nagata S, Yamaguchi T. Aortigenic embolic stroke: a transesophageal echocardiographic approach. Stroke 1992; 23(8): 1056-61

17-R E Scharf, M Hennerici, V Bluschke, J Lueck and R G Kladetzky Cerebral ischemia in young patients: it is associated with mitral valve prolapse and abnormal platelet activity in vivo? 1982; 13: 454-458

18- Nishamura RA, McGoon MD, Shub C. Echocardiographically documented

mitral-valve prolapse. N Engl J Med 1985;313:1305 \pm .

19-Jean-Francois Avierinos, Robert D. Brown, David A. Foley, Vuyisile Nkomo, George W. Petty, Christopher Scott, MS; Maurice EnriquezSarano, . Cerebral Ischemic Events After Diagnosis of Mitral Valve Prolapse. Stroke. 2003; 34: 1339-1344.

20- Dan Gilon, Ferdinando S. Buonanno, Marshall M. Joffe , Marcia Leavitt, B.S., Jane E. Marshall., J. Philip Kistler, and Robert A. Levine. Lack of Evidence of an Association between Mitral-Valve Prolapse and Stroke in Young Patients.N Engl J Med 1999; 341:8-13.

21-Boudoulas K.D., Boudoulas H. Floppy Mitral Valve (FMV)/Mitral Valve Prolapse (MVP) and the FMV/MVP Syndrome: Pathophysiologic Mechanisms and Pathogenesis of Symptoms. Cardiology 2013;126:69-80 .

22- Lechat PH, Mas JL, Lascault G, et al. Prevalence of patent foramen ovale in patients with stroke. N Engl J Med. 1988;318:1148-52.

23- Michael Handke, Andreas Harloff, Manfred Olschewski, Andreas Hetzel, and Annette Geibel. Patent Foramen Ovale and Cryptogenic Stroke in Older Patients. N Engl J Med 2007; 357:2262-2268).
24-Berthet K, Lavergne $\mathrm{T}$, Cohen $\mathrm{A}$, et al. Significant association of atrial vulnerability with atrial septal abnormalities in young patients with ischemic stroke of unknown cause. Stroke. 2000;31:398-403.

25-Jin Oh Na, Seung Yong Shin, Hong Euy Lim1, Cheol Ung Choi1, Seong Hwan Kim, Jin Won Kim, Eung Ju Kim, Eun Mi Lee, Seung-Woon Rha, Chang Gyu Park, Hong Seog Seo, Dong Joo $\mathrm{Oh}$ and Young-Hoon Kim. Impaired transport function of the left atrium and left atrial appendage in cryptogenic stroke patients with atrial septal aneurysm and without patent foramen ovale. Eur J Echocardiogr (2011) 12 (2): 140-147.

26-Bannan A, Shen R, Silvestry FE, Herrmann HC. Characteristics of adult patients with atrial septal defects presenting with paradoxical embolism. Catheter Cardiovasc Interv. 2009 Dec 1;74(7):1066-9. 2009 Dec 1;74(7):1066-9.

27-Kate C. Young,and Curtis G. Benesch. Transesophageal Echocardiography Screening in Subjects with a First Cerebrovascular Ischemic Event. J Stroke Cerebrovasc Dis. 2012 November 1.

28-Russo C., Jin Z., Rundek T., Homma S., Sacco R.L., Di Tullio M.R.; Atherosclerotic disease of the proximal aorta and the risk of vascular events in a population-based cohort: the Aortic Plaques and Risk of Ischemic Stroke (APRIS) study. Stroke. 40 2009:2313-2318.

29-S. Goya Wannamethee, A. Gerald Shaper,S. Ebrahim . HDL-Cholesterol, Total Cholesterol, and the Risk of Stroke in Middle-Aged British Men. Stroke. 2000 Aug;31(8):1882-8.

30- Rojas JI, Zurrú MC, Romano M, Patrucco L, Cristiano E. Acute ischemic stroke and transient ischemic attack in the very old--risk factor profile and stroke subtype between patients older than 80 years and patients aged less than 80 years. Eur J Neurol. 2007 Aug;14(8):895-9.

31- Cholesterol Treatment Trialists' (CTT) Collaborators.Efficacy and safety of cholesterollowering treatment: prospective meta-analysis of data from 90056 participants in 14 randomised trials of statins. LANCET. 2005 October ;366 (9493): 1267-1278.

32- Gaia Sirimarco, Dominique Deplanque, Philippa C. Lavallée, Julien Labreuche, Elena Meseguer, Lucie Cabrejo,Céline Guidoux, Jean-Marc Olivot, Halim Abboud, Bertrand Lapergue, Isabelle F. Klein,Mikael Mazighi,Pierre-Jean Touboul, Eric Bruckert, Pierre Amarenco. Atherogenic Dyslipidemia in Patients With Transient Ischemic Attack. Stroke. 2011; 42: 2131-2137.

33- Heiss G, Tamir I, Davis CE, Tyroler HA, Rifkind BM, Schonfeld G, Jacobs D, Frantz ID. Lipoprotein-cholesterol distributions in selected 
North America populations: the Lipid Research Clinics Program Prevalence Study. Circulation.. 1980;61:302-315.

34-Moulopoulos SD, Andamopoulos PN, Diamantopoulos EI, Nanas SN, Anthopoulos LN, Iliadi-Alexandrou M. Coronary heart disease risk factors in a random sample of Athenian adults: the Athens Study. Am J Epidemiol.. 1987; 126:882-892.

35-Heitmann BL. The effects of gender and age on associations between blood lipid levels and obesity in Danish men and women aged 35-65 years. J Clin Epidemiol.. 1992;45:693-702.

36-Schaefer EJ, Lamon-Fava S, Cohn SD, Schaefer MM, Ordovas JM, Castelli WP, Wilson PWF. Effects of age, gender, and menopausal status on plasma low density lipoprotein cholesterol and apolipoprotein B levels in the Framingham Offspring Study. J Lipid Res.. 1994;35:779-792.

37-Newschaffer CJ, Bush TL, Hale W: Aging and total cholesterol levels: cohort, period, and survivorship effects. Am J Epidemiol.. 1992;136:23-34.

38-Frishman WH, Ooi WL, Derman MP, Eder HE, Gidez LI, Ben-Zeev D, Zimetbaun P, Heiman M, Aronson M. Serum lipids and lipoprotein in advanced age: intraindividual changes. Ann Epidemiol.. 1992;2:43-50.

39-Garry PJ, Hunt WC, Koehler KM, VanderJagt DJ, Vellas BJ. Longitudinal study of dietary intakes and plasma lipids in healthy elderly men and women. Am J Clin Nutr.. 1992;55:682-688

40-Bowman TS, Sesso HD, Ma J, Kurth T, Kase CS, Stampfer MJ, Gaziano JM: Cholesterol

and the risk of ischemic stroke. Stroke 2003; 34: 2930-2934.

41-Sridharan R: Risk factors for ischemic stroke: a case control analysis. Neuroepidemiology 1992; 11: 24-30.

42- Shahar E, Chambless LE, Rosamond WD, Bolland LL, Ballantyne CM, McGovern PG,

Sharrett AR: Plasma lipid profile and incident ischemic stroke. The Atherosclerosis Risk in Communities (ARIC) Study. Stroke 2003; 34: 623-631.

43- Tanne D, Koren-Morag N, Graff E, Goldbourt U, the BIP Study Group: Blood lipids and firstever ischemic stroke/transient ischemic attack in the Bezafibrate Infarction.Prevention (BIP) Registry: high triglycerides constitute an independent risk factor. Circulation 2001; 104: 2892-2897.

44- Patel A, Barzi F, Jamrozik K, Lam TH, Ueshima H, Whitlock G, Woodward M, Asia Pacific Cohort Studies Collaboration: Serumtriglycerides as a risk factor for cardiovascular diseases in the Asia-Pacific region. Circulation 2004; 110: 2678-2686.

45- Anette Varbo , Børge G. Nordestgaard, Anne Tybjærg-Hansen, Peter Schnohr, Gorm B. Jensen, Marianne Benn : Nonfasting triglycerides, cholesterol, and ischemic stroke in the general population. Annals of Neurology (2011); 69(4): 628-634.

46-Marco R. Di Tullio, Cesare Russo,Zhezhen Jin, Ralph L. Sacco, J.P. Mohr, Shunichi Homma. Aortic Arch Plaques and Risk of Recurrent Stroke and Death. Circulation. 2009; 119: 23762382

47-Kleindorfer D, Panagos P, Pancioli A, et al. Incidence and short-term prognosis of transient ischemic attack in a population-based study. Stroke. Apr 2005;36(4):720-3.

48- Ayeesha Kamran Kamal' Ahmed Itrat , Muhammed Murtaza, Maria Khan, Asif Rasheed, Amin Ali, Amna Akber, Zainab Akber, Naved Iqbal, Sana Shoukat, Farzin Majeed and Danish Saleheen The burden of stroke and transient ischemic attack in Pakistan: a community-based prevalence study. BMC Neurology 2009, 9:58 .

49- Huang H.W. · Guo M.H. · Lin R.J. · Chen Y.L. • Luo Q. · Zhang Y. · Wong K.S. : Prevalence and Risk Factors of Middle Cerebral Artery Stenosis in Asymptomatic Residents in Rongqi County, Guangdong. Cerebrovasc Dis 2007;24:111-115.

50- Jukka Putaala, Antti J. Metso, Tiina M. Metso, Nina Konkola, Yvonn Kraemer, Elena Haapaniemi, Markku Kaste and Turgut Tatlisumak: Analysis of 1008 Consecutive Patients Aged 15 to 49 With First-Ever Ischemic Stroke: The Helsinki Young Stroke Registry. Stroke. 2009;40:1195-1203.

51-Margaret Kelly-Hayes, Alexa Beiser, Carlos S Kase, Amy Scaramucci, Ralph B D'Agostino,Philip A Wolf. The influence of gender and age on disability following ischemic stroke: the Framingham study. Volume 12, Issue 3, May-June 2003, Pages 119-126 


\section{فحص القلب بالموجات فوق الصوتيه باستخدام المجس المريئي فى مرضى السكتة الدماغية

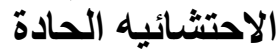

السكتة الدماغية هي من بين الأسباب الأكثر شيوعا للمرض و الأبه الأيات في العالم. و من قواعد البيانات الخاصة بمرضى السكتة الدماغية

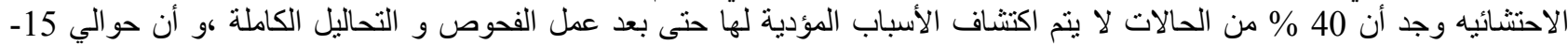

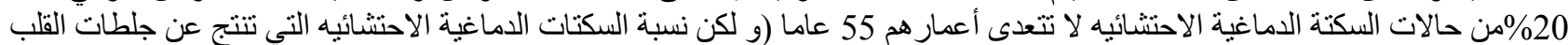
لم بتم تحديدها بدقة حتى الان) الانكة). و قد أوصت بعض الدر اسات بعمل الموجات فوق الصات الصونية بالمجس المريئيي لكل حالات السكتة الدماغية الاحتشائيه لقلة تكلفته و حساسيته في

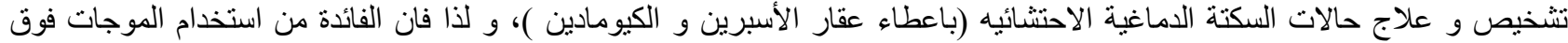

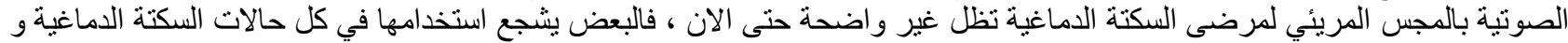

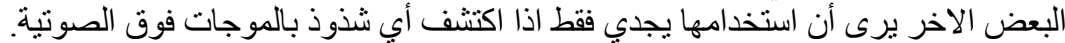

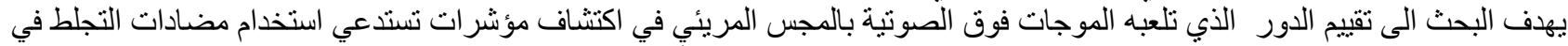

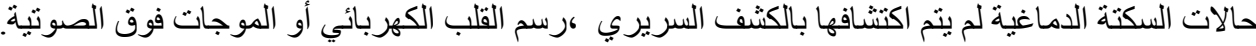

100 معاييز الادراج: 100 مريضون من سكتة دماغية احتشائيه و دون دلائل تستدعي استخدام مميعات الدم (بناء على الكثف السريري ، رسم القلب

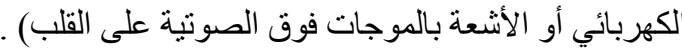

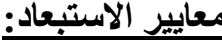

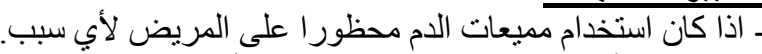

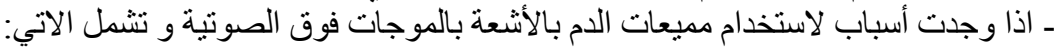
*وجود صمامات القلب الصناعية.

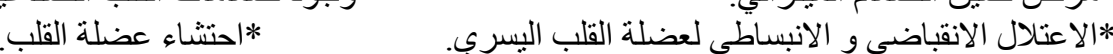

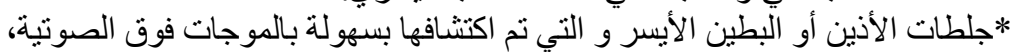

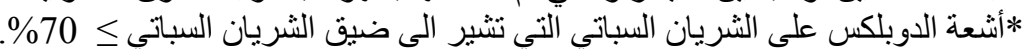

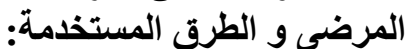

تم عمل هذا البحث في مستشفيات جامعة الزقازيق و شمل مائة مريض يعانون من سكتة دماغية احتشائيه وتم عمل الاتي لكل

1- أخذ مو افقة المريض على اجر اء الفحص . 2- أخذ التاريخ المرضي بالكامل و الفحص الاكلينيكي الثامل،

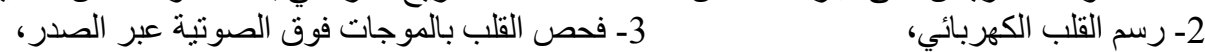
4- فحص القلب بالموجات فوق الصوتية بالمجس المريئي و سوف بشمل الفحص البحث عن المصادر المحتملة التالية للانسداد:

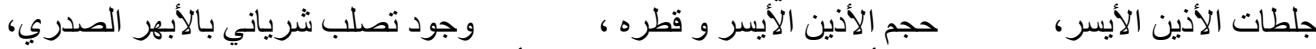

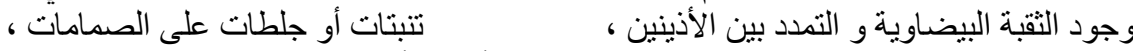
قياس سرعة تدفق الدم و البحث عن جلطات بملحق اللاذين الأيسر.

معدل انتشار هبوط الصمام الميتر الي و الثقبة البيضوية البر اءة أعلى في مرضى السكتة الدماغية الاحتشائيه صغار السن .

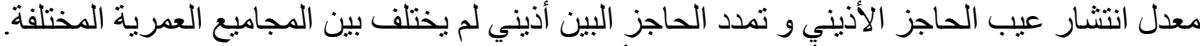

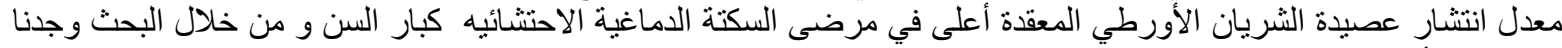

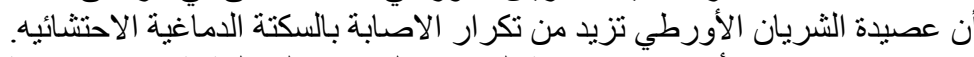

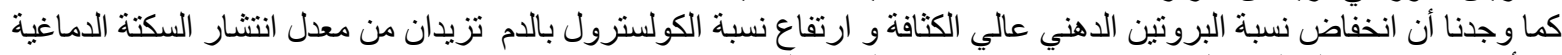

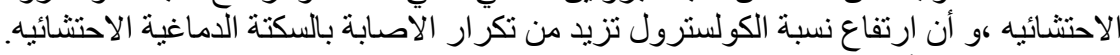

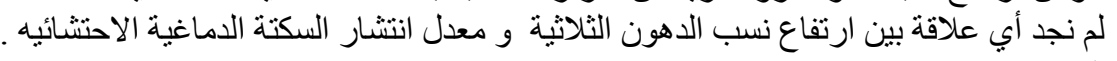

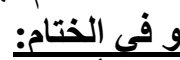

نحب أن نوضنح أن هذه النتائج تدل على أن الأشعة بالموجات الصوتية عن طريق المجس المريئي لها أهمية كبرى في تشخيص أسباب الجلطة

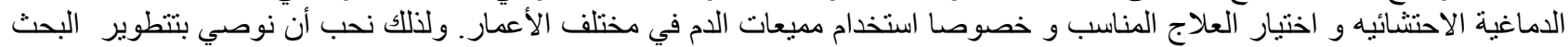
على نطاق أوسع و على عدد أكبر من المرضى النه.و عمل ابحاث تداخلية باستخدام مميعات الدم و متابعة المرضى عن طريف أشعة الموجات الصوتية بالمجس أسع ولى المريئي 